\title{
Evaluation of Anti-Cancer Properties of Pegylated Ethosomal Paclitaxel on Human Melanoma Cell Line SK- MEL-3
}

\author{
Elham Bagheri Eskolaky ${ }^{1}$, Mehdi Ardjmand ${ }^{2}$ and Azim Akbarzadeh ${ }^{3 *}$ \\ ${ }^{1}$ Department of Applied Chemistry, Faculty of Pharmaceutical Chemistry, Pharmaceutical Sciences Branch, ${ }^{2}$ Chemical \\ Engineering Department, Islamic Azad University, South Tehran Branch, ${ }^{3}$ Department of Pilot Nanobiotechnology, Pasteur \\ Institute of Iran, Tehran, Iran
}

*For correspondence: Email: azimakbarzadeh1326@gmail.com; Tel: +982166465406, +989128387017; Fax: +82166465132

\begin{abstract}
Purpose: To prepare pegylated ethosomal Paclitaxe $\AA^{\circledR}$ by reverse phase evaporation technique, and evaluate its cytotoxic effect on SK-MEL-3 cell line.

Methods: Nanodrug was prepared by reverse phase evaporation technique. The characteristics of the nanoparticles were evaluated by a zetasizer and scanning electron microscopy (SEM). Drug loading and encapsulation efficiency as well as paclitaxe/® release were determined spectrophotometerically at $227 \mathrm{~nm}$ while the cytotoxicity of the pegylated ethosomal nanoencapsulated Paclitaxe/ $($ was determined by 3-(4,5-dimethylthiazol-2-yl)-2,5-diphenyltetrazolium bromide (MTT) assay on SK-MEL-3 cell line.

Results: The mean diameter and zeta potential of drug-loaded pegylated ethosomal particles and blank pegylated ethosomes were $138.1 \pm 2.7 \mathrm{~nm}$ and $-13.1 \mathrm{mV}$, and $102.3 \pm 2.1 \mathrm{~nm}$ and $-19.2 \mathrm{mV}$, respectively, while drug loading and encapsulation efficiency were $2.82 \pm 0.27$ and $96 \pm 1.27 \%$, respectively. The drug release pattern indicates that the half-life (t1/2) of the nanodrug was approximately twice that of the free drug for both static and dynamic release. Toxicological results indicate approx. 4.5-fold cytotoxicity against SK-MEL-3 cell line compared with the free drug.

Conclusion: This study shows that pegylated ethosomal Paclitaxe $\mathbb{B}^{\circledR}$ is significantly considerably more toxic than the free drug on SK-MEL-3 cell line, thus making it an potential alternative to the standard therapy. It is, however, necessary to evaluate the nanoformulation in vivo.
\end{abstract}

Keywords: Paclitaxe/®, Ethosome, Reverse phase evaporation, Pegylated, Cytotoxicity, Nanoparticles, Drug release

Tropical Journal of Pharmaceutical Research is indexed by Science Citation Index (SciSearch), Scopus, International Pharmaceutical Abstract, Chemical Abstracts, Embase, Index Copernicus, EBSCO, African Index Medicus, JournalSeek, Journal Citation Reports/Science Edition, Directory of Open Access Journals (DOAJ), African Journal Online, Bioline International, Open-J-Gate and Pharmacy Abstracts

\section{INTRODUCTION}

Therapeutic nanoparticles are solid colloidal particles ranging from $1-1000 \mathrm{~nm}$. They are essentially macromolecules in that an active substance (drug or bioactive material) is entrapped, dissolved, encapsulated or attached to them [1]. Nanoparticles can produce controlled release, mask physicochemical properties, reduce drug toxicity and improve bioavailability, efficacy and biodistribution of the active substance [2].

Paclitaxel $\circledast$ is a potent anticancer agent, but its clinical use of the drug is limited due to low solubility and poor gastrointestinal absorption [3]. To increase solubility, the drug is mixed with Cremophor EL and alcohol under the trade 
names, Taxol $\circledast$ or Paxene $\AA$. Cremophor EL is a solvent for biological and pharmacological substances but has various side effects, such as hypersensitivity, nephrotoxicity, neurotoxicity and hyperlipidemia, as well as alters the pharmacokinetics of Paclitaxel ${ }^{\circledR}$ [4]. Therefore, the use of nanotechnology-based devices as Paclitaxel $\circledast$ carriers is recommended to enhance therapeutic efficacy and decrease the side effects of the drug [5]. Based on this approach, an approved formulation of Paclitaxel $₫$ by Food and Drug Administration (FDA) under the trade name of Abraxane $\AA$ has been prepared. Abraxane ${ }^{\circledR}$ - a free Cremophor $E L$ and an albumin-bound Paclitaxel $\AA$ nanoparticle is used to treat recurrent metastatic breast cancer [6] .

Ethosome is a type of nanoparticulate platform, which is actually a liposomal nanoparticle. Due to significant skin penetration, ethosomes have been extensively used for drug delivery to skin [7]. They have also been used in systemic drug delivery to treat HIV infections, shaking palsy, angiocardiopathy and topical delivery of various drugs. Enhancement of skin penetration makes ethosomes suitable drug carriers for skin-related diseases, such as skin carcinoma and psoriasis. Two properties facilitate nanoparticle penetration of skin. First, the ethanol in ethosomes increases lipidic membrane fluidity of skin cells. Second, deformability also enhances skin penetration by nanoparticles [8].

Malignant melanoma is the most aggressive form of skin cancer. The outbreak of the disease is faster than any type of cancer worldwide. Early detection, chemotherapy and surgery are the treatment options of the disease. However, prognosis for metastatic melanoma is poor [9]. Many researchers studied Paclitaxel ${ }^{\circledR}$ as a chemotherapeutic agent for the treatment of melanoma $[10,11]$. In this study, the study was to develop and characterize Paclitaxel@-loaded ethosome nanoparticles and compare the efficacy of the nanodrug with that of the free drug form on human melanoma SK-MEL-3 cell line.

\section{EXPERIMENTAL}

\section{Materials}

Paclitaxel $\circledast$, cholesterol, phosphatidylcholine and MTT $(0.5 \mathrm{mg} / \mathrm{mL})$ were purchased from Sigma Company (Sigma, USA). Polyethylene glycol 3350 (PEG3350) and RPMI-1640 medium were obtained from Emrooz Chemical Industries (Kimiagaran Emrooz Chem. Ind., Iran) and Invitrogen (USA), respectively. Isopropanol and ethanol $99.4 \%$ were purchased from Merck (Germany). SK-MEL-3 cell line was supplied by Pasteur Institute of Iran. All other materials were of analytical grade. De-ionized water was used all through the study.

\section{Preparation of nanoparticles}

Nanoparticles were prepared using the reverse phase evaporation technique in order to synthesize ethosome with a high level of encapsulation efficiency [12].

Paclitaxel $\AA$, cholesterol, PEG3350 and phosphatidylcholine (1:6.5:9:28 weight ratio) were dissolved in deionized water and ethanol $99.4 \%$ (67.5:32.5 volumetric ratio). Then, the resultant solution was stirred (100 rpm, $37{ }^{\circ} \mathrm{C}$ ) to obtain a clear yellow suspension. Later, the formulation was sonicated in a bath sonicator (50 W, Bandelin Sonopuls HD 2070, Bandelin Elec., Germany) for $6 \mathrm{~min}$ in order to reduce the size of ethosome [13]. A similar procedure was also used for preparation of a control solution without drug.

\section{Characterization of nanoparticles}

Mean diameter, size distribution and Zeta potential of particles were determined using Zetasizer (Zen 3600; Malvern Instruments Ltd, Malvern Worcestershire, UK) and Zetaplus (Brookhaven instrument corp., USA). The morphology of nanoparticles was studied using Scanning Electron Microscope (FE-SEM; Hitachi S-4150; Japan).

\section{Drug loading and encapsulation efficiencies}

In order to determine drug loading and encapsulation efficiencies, $2 \mathrm{~mL}$ of the pegylated form of ethosome nanoparticles that was loaded with Paclitaxel $\Omega$ was centrifuged at $14000 \mathrm{rpm}$ and $-4{ }^{\circ} \mathrm{C}$ for $60 \mathrm{~min}$ (Sigma laborazentrifuge, Germany). The concentration of the drug in supernatant was determined by spectrophotometrically (Shimadzu UV - 1601PC, Germany) at $227 \mathrm{~nm}$ Drug encapsulation (EE) and loading (LE) efficiencies were calculated as in Eqs 1 and 2 , respectively.

$E E(\%)=\{(D i-D s) / D i\} 100$

where $\mathrm{Di}$ is the initial drug concentration (in $\mathrm{mg} / \mathrm{ml}$ ) and Ds is the drug concentration in the supernatant (in $\mathrm{mg} / \mathrm{ml}$ ).

$\operatorname{LE}(\%)=\mathrm{Dn} / \mathrm{Wn}) 100$

where $\mathrm{Dn}$ is the amount of drug in the nanoparticles (in $\mathrm{mg}$ ) and $\mathrm{Wn}$ the weight. 


\section{In vitro drug release studies}

In order to study the release pattern of Paclitaxel囚, membrane diffusion technique was used. For this purpose, equal concentrations of pegylated ethosomal drug and standard drug solutions $(1 \mathrm{~mL})$ were poured into two separate dialysis bags (mol wt cut-off of $12000 \mathrm{Da}$, Sigma, USA). Thereafter, the dialysis bags were submerged in two separate graduated cylinder each containing $25 \mathrm{~mL}$ of PBS ( $\mathrm{pH}=7.4)$ and stirred $\left(100 \mathrm{rpm}, 37^{\circ} \mathrm{C}\right)$. The amount of released drug in buffer phosphate was measured spectrophotometrically at various time intervals. At time intervals, a $2 \mathrm{ml}$ sample of the release medium was removed and replaced with fresh buffer to maintain the constant volume. Then, cumulative drug release versus time was calculated.

\section{In vitro cytotoxicity studies}

The cytotoxicity of Paclitaxel® loaded into pegylated ethosomal nanoparticles was determined by MTT assay in SK-MEL-3 cell line on 96-well plates. Cells were seeded in dilution rate of $1 \times 10^{4}$ for each well in RPMI-1640 medium containing $10 \%$ fetal bovine serum and $1 \%$ penicillin/streptomycin $\left(37{ }^{\circ} \mathrm{C}, 5 \% \mathrm{CO}_{2}\right)$. They were allowed to attach for $48 \mathrm{~h}$. Thereafter, culture media were removed and cells were treated with free Paclitaxel ${ }^{\circledR}$ and pegylated

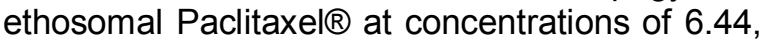
$3.22,1.61,0.805,0.4025,0.20125$ and 0.100625 $\mu \mathrm{M}$. After $24 \mathrm{~h}$, the drug containing culture was removed and $80 \mu \mathrm{L}$ MTT solutions $(0.5 \mathrm{mg} / \mathrm{mL}$, $\mathrm{pH}$ 7.4) was added to each well and incubated for $2 \mathrm{~h}$. Later, MTT was discarded and $100 \mu \mathrm{L}$ isopropanol $100 \%$ was added to dissolve the formazan crystals. Finally, absorbance was read at $540 \mathrm{~nm}$ in an Elisa reader (BioTek Instruments, VT, USA). $I_{50}$ was measured by statistical package Pharm-PCS software.

\section{Statistical analysis}

The results are expressed as mean \pm standard deviation ( $S D, n=3$ ). The data were statistically analyzed by one-way analysis of variance (ANOVA) using IBM Statistics SPSS software version 19, and statistical significance was set at $p<0.05$.

\section{RESULTS}

\section{Characteristics of nanoparticles}

Size, size distribution and zeta potential of the nano drug and the blank nanoparticles are presented in Table 1. Nanoparticle morphology, based on SEM indicates the suitability of the preparation method as the micrographs showed well-ordered vesicles (Figure 1).

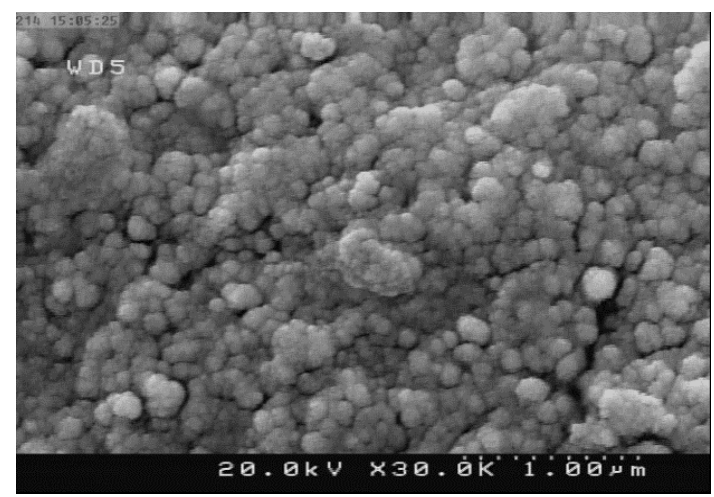

Figure 1: SEM image of pegylated ethosomal Paclitaxe ${ }^{\circledR}$ nanoparticles prepared by reverse phase evaporation technique $(\times 30,000)$

\section{In vitro drug release}

The amount of dynamically and statically released Paclitaxel $\circledast$ from pegylated ethosomal formulation and standard drug after definite time intervals over a period of 2 days are displayed in Figures 2 and 3.

\section{In vitro cytotoxicity}

The cell viability of Paclitaxel $\circledast$ and Paclitaxel $($ loaded ethosome nanoparticles on SK-MEL-3 cell line after $24 \mathrm{~h}$ incubation is illustrated in Figure 3.

The maximum cytotoxic effect of pegylated

Table 1: Physicochemical properties of pegylated nanoethosomal Paclitaxel ${ }^{\circledR}$

\begin{tabular}{lccc}
\hline Formulation & $\begin{array}{c}\text { Mean diameter } \\
(\mathbf{n m})^{*}\end{array}$ & $\begin{array}{c}\text { Zeta potential } \\
(\mathbf{m V})^{*}\end{array}$ & $\begin{array}{c}\text { Polydispersity } \\
\text { index (PDI)* }\end{array}$ \\
\hline $\begin{array}{l}\text { Pegylated ethosomal } \\
\text { nanoparticles with drug }\end{array}$ & $138.1 \pm 2.7$ & -13.1 & 0.1 \\
$\begin{array}{l}\text { Pegylated ethosomal } \\
\text { nanoparticles without drug }\end{array}$ & $102.3 \pm 2.1$ & -19.2 & 0.12 \\
\hline All the data are presented as mean $\pm S D(n=3)$ & &
\end{tabular}


ethosomal Paclitaxel $($ nanoparticles and the free drug on SK-MEL-3 cell line after $24 \mathrm{~h}$ of were 1.8 \pm 0.1 and $8.2 \pm 1.01$, respectively.

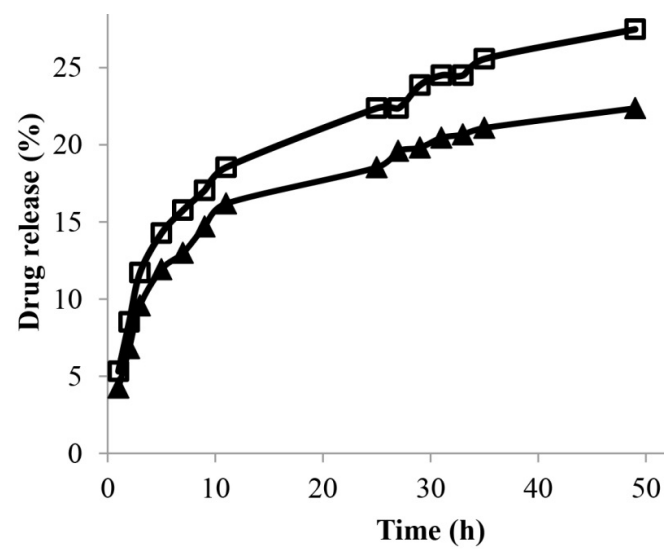

Figure 2: Release profile of free form of Paclitaxel ${ }^{\circledR}$ obtained by static $(\boldsymbol{\Delta})$ and dynamic ( $\square$ ) release methods

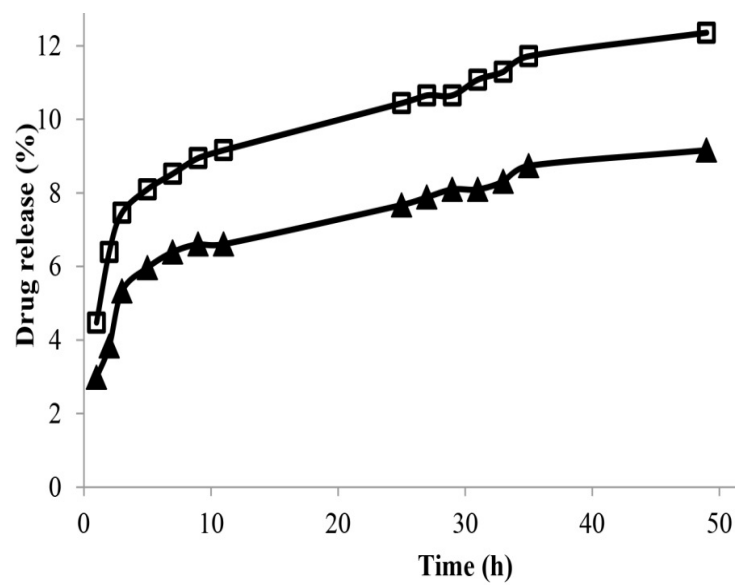

Figure 3: Release pattern of Paclitaxel $^{\circledR}$ from pegylated ethosomal nanoparticles obtained by static ( $\Delta$ ) and dynamic ( $\square$ ) release methods

\section{DISCUSSION}

Ethosomes are safe lipidic nanoparticles composed of phospholipid and high concentrations of water and ethanol $(20-45 \%)$. The property of skin penetration of ethosomes has attributed to the synergism between the particles, ethanol and skin lipids [14].

Nanoparticles were approximately homogenous that confirmed by zetasizer. Sonication caused the nanoparticles to become smaller and more uniform. However, it has been observed that the size of the nanoparticles was higher than that of the blank nanoparticles. This phenomenon has also been observed in a previous study [15].

In addition, the zeta potential of the nanoformulation was more positive than the blank nanoparticles, thus indicating the positive charge of Paclitaxel®.

In both formulations, a burst release occurred in the first $3 \mathrm{~h}$. Release rate was gradually decreased which may come from presence of PEG. However, the rate of dynamic release of drug was more prominent compared to static in which $12.4 \%$ and $27.5 \%$ of drug dynamically released, while $9.2 \%$ and $22.4 \%$ of drug was statically released from pegylated ethosomal Paclitaxel $\circledast$ and the free drug formulations, respectively.

Otsuka et al also found that the presence of polyethylene glycol can lead to enhancement of stability, and consequently increased drug delivery to the tumor and hence improvement in therapeutic efficacy [16].

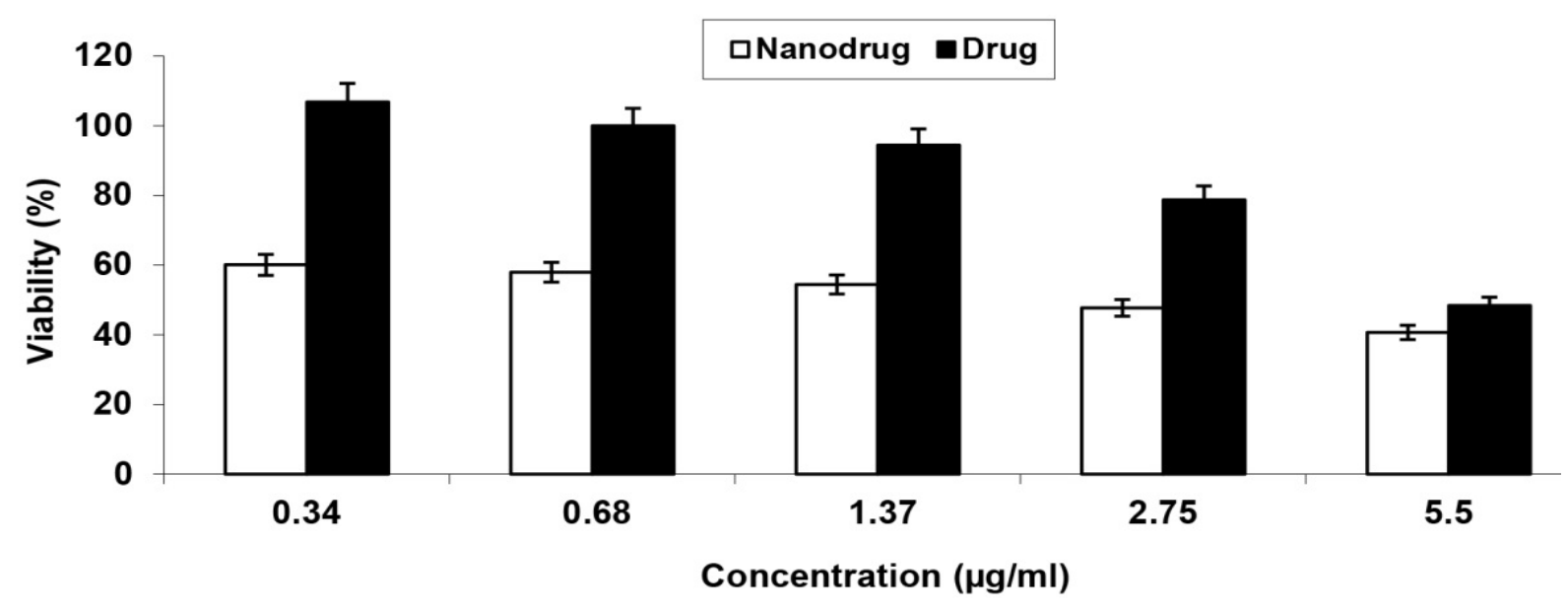

Figure 4: Cell viability of Paclitaxel ${ }^{\circledR}$ and Paclitaxe ${ }^{\circledR}$-loaded ethosome nanoparticles on SK-MEL-3 cell line, compared with control, after $24 \mathrm{~h}$ incubation 
MTT assay is a valid test to evaluate the efficacy of the nanoformulation in vitro, and hence it was used in the present study to assess the cytotoxicity of Paclitaxel $\circledast$ on melanoma cell line SK-MEL-3. The nanoformulation decreased cell viability by $33 \%$ compared with the free form.

The results showed the $I_{50}$ of pegylated ethosome formulation for SK-MEL-3 cell line is less than that of the standard drug. Based on the definition of $\mathrm{IC}_{50}$ (8.2 free drug against 1.8 of nanoformulation), the cytotoxicity of the nanoformulation against SK-MEL-3 is about 4.5 times of that of the free drug.

\section{CONCLUSION}

Reverse phase evaporation technique is a suitable method for the preparation of Paclitaxel® nanoparticles. The formulated nanodrug has a longer half-life and stronger cytotoxic effect than the free drug form. However, in vivo studies are required to ascertain the potentials of the developed formulation in chemotherapy.

\section{REFERENCES}

1. Leyva-Gómez G, Cortés H, Magaña JJ, Leyva-García N, Quintanar-Guerrero $D$, Florán B. Nanoparticle technology for treatment of Parkinson's disease: the role of surface phenomena in reaching the brain. Drug Discov Today 2015. doi: 10.1016/j. drudis. 2015.02.009.

2. Kreuter J. Drug delivery to the central nervous system by polymeric nanoparticles: what do we know? Adv Drug Deliv Rev 2014; 71: 2-14.

3. Agüeros $M$, Zabaleta $V$, Espuelas $S$, Campanero MA, Irache JM. Increased oral bioavailability of paclitaxel by its encapsulation through complex formation with cyclodextrins in poly (anhydride) nanoparticles. J Control Release 2010; 145: 2-8.

4. Sharma S, Verma A, Teja BV, Shukla P, Mishra PR. Development of stabilized Paclitaxel nanocrystals: Invitro and in-vivo efficacy studies. Eur J Pharm Sci 2015; 69: 51-60.
5. Zhang $W$, Shi $Y$, Chen $Y$, Ye J, Sha $X$, Fang $X$. Multifunctional Pluronic P123/F127 mixed polymeric micelles loaded with paclitaxel for the treatment of multidrug resistant tumors. Biomaterials 2011; 32: 2894-2906.

6. Bernabeu E, Helguera G, Legaspi MJ, Gonzalez L, Hocht C, Taira C, Chiappetta DA. Paclitaxel-loaded PCLTPGS nanoparticles: in vitro and in vivo performance compared with Abraxane®. Colloids Surf $B$ Biointerfaces 2014; 113: 43-50.

7. Ainbinder D, Paolino D, Fresta M, Touitou E. Drug delivery applications with ethosomes. J Biomed Nanotechnol 2010; 6: 558-568.

8. Zhang $Y T$, Shen $L N$, Wu ZH, Zhao JH, Feng NP. Evaluation of skin viability effect on ethosome and liposome-mediated psoralen delivery via cell uptake. J Pharm Sci 2014; 103: 3120-3126.

9. Monge-Fuentes $V$, Muehlmann LA, de Azevedo RB. Perspectives on the application of nanotechnology in photodynamic therapy for the treatment of melanoma. Nano Rev 2014; 5.

10. Hersh EM, O'Day SJ, Ribas A, Samlowski WE, Gordon MS, Shechter DE, Clawson AA, Gonzalez R. A phase 2 clinical trial of nab-paclitaxel in previously treated and chemotherapy-naive patients with metastatic melanoma. Cancer 2010; 116: 155-163.

11. Walker L, Schalch $H$, King DM, Dietrich L, Eastman M, Kwak M, Kim K, Albertini MR. Phase II trial of weekly paclitaxel in patients with advanced melanoma. Melanoma Res 2005; 15: 453-459.

12. Himanshu A, Sitasharan $P$, Singhai AK. Liposome- as drug carriers. Int J Pharm Life Sci 2011; 2: 945-951.

13. Yang T, Choi MK, Cui FD, Kim JS, Chung SJ, Shim CK, Kim DD. Preparation and evaluation of paclitaxelloaded PEGylated immunoliposome. J Control Release 2007; 120: 169-77.

14. Zhang Z, Wo Y, Zhang $Y$, Wang $D$, He R, Chen $H$, Cui D. In vitro study of ethosome penetration in human skin and hypertrophic scar tissue. Nanomedicine: Nanotechnology, Biology and Medicine 2012; 8: 1026-1033.

15. Cooper DL, Harirforoosh S. Design and optimization of PLGA-based diclofenac loaded nanoparticles. PLoS One 2014; 9: e87326.

16. Otsuka H, Nagasaki Y, Kataoka K. PEGylated nanoparticles for biological and pharmaceutical applications. Adv Drug Deliv Rev 2003; 55: 403-419. 